\title{
Educators who believe: understanding the enthusiasm of teachers who use digital games in the classroom
}

\author{
Colleen Stieler-Hunt* and Christian M. Jones \\ Engage Research Cluster, School of Social Sciences, Faculty of Arts and Business, \\ University of the Sunshine Coast, Sippy Downs, QLD, Australia
}

(Received 29 September 2014; final version received 27 July 2015)

\begin{abstract}
This study used qualitative methods to explore why some educators embrace the use of digital game-play (DGP) in the classroom. The results indicated that these teachers had a very strong belief that DGP could be beneficial for learning which stemmed from experiencing their own form of subjective success with using DGP in the classroom, availing themselves of information and advocacy about using DGP in the classroom and personal experiences with DGP either through their own DGP or through watching their own children play games. They also shared positive attitudes towards information and communication technologies generally and had initially been invited to use DGP in the classroom by someone in authority. Their use of DGP was also something that they felt made them different to other teachers. Applying these findings to Rogers' Diffusion of Innovations theory predicted that the diffusion rate of using DGP in the classroom will continue to be slow. Finally, this study indicates that teachers need to experience their own form of subjective 'success' in order to find DGP valuable and this subjective 'success' often goes beyond test score performance.
\end{abstract}

Keywords: game-based learning; video games; elementary education; secondary education; educational beliefs; pedagogical issues

\section{Introduction}

Worldwide, there are many initiatives that encourage teachers to use digital games (DGs) in primary and secondary school classrooms (see Chee 2012; Department of Education and Early Childhood Development (Victoria) 2013; Haas 2008; McFarlane, Sparrowhawk, and Heald 2002; Microsoft Research 2010; Queensland Government 2008; Scottish Government 2014a, 2014b; The Joan Ganz Cooney Center 2014a, 2014b; Zagami 2012). The state education department of Queensland, Australia ran a games in learning program encompassing four overlapping strands: digital game-play (DGP), game-study, game-making and game innovation (Queensland Government 2008). This research is focused on DGP.

For the purpose of this study, we will define a game as 'a system in which players engage in an artificial conflict, defined by rules, that results in a quantifiable outcome' (Salen and Zimmerman 2003). By DGs, we mean any game that uses electronic hardware to deliver some or all of the game. This includes video games played on

*Corresponding author. Email: cstieler@usc.edu.au

Responsible Editor: Meg O’Reilly, Southern Cross University, Australia

Research in Learning Technology 2015. (C) 2015 C. Stieler-Hunt and C.M. Jones. Research in Learning Technology is the journal of the Association for Learning Technology (ALT), a UK-based professional and scholarly society and membership organisation. ALT is registered charity number 1063519. http://www.alt.ac.uk/. This is an Open Access article distributed under the terms of the Creative Commons Attribution 4.0 International License (http://creativecommons.org/licenses/by/4.0/), allowing third parties to copy and redistribute the material in any medium or format and to remix, transform, and build upon the material for any purpose, even commercially, provided the original work is properly cited and states its license. 
home and handheld consoles, PC games, web-games, mobile phone games and games such as alternate reality games that blend the analogue and digital worlds. DGP refers to the act of participating in a DG.

Although views vary on the value of using DGP in the classroom (Kirriemuir and McFarlane 2004), proponents believe that DGP can promote deep learning (Gee 2008), can effectively support learning and, further, the educational advantages afforded by thoughtfully selected and effectively used DGP warrant consideration for all classrooms (Van Eck 2006). This paper explores one theme that emerged from qualitative research into the experiences of teachers using DGP in the classroom: Why do some educators embrace DGP in the classroom? It responds to Bourgonjon et al. (2013)'s call for qualitative research that focuses on teachers with experience using DGP in the classroom.

\section{Method}

The data used for this study were in-depth, semi-structured interviews which ranged from 1 to 2 hours in duration and were conducted with 13 (eight female, five male) educators that have used DGP in the classroom. All participants interviewed had worked within the educational system of Queensland, Australia. A convenience sample was used whereby potential participants responded to an invitation sent to a Queensland-based games in learning email list or were approached through professional networks. Where possible and practical, the order of the interviews was guided by Theoretical Sampling. That is, we chose subsequent participants with the intent to answer questions we had about concepts emerging from analysis of the existing data (Corbin and Strauss 2008). The educators were in different stages of their educational careers from beginning teachers to retirees to educational advisors, and from diverse educational settings ranging from primary schools to secondary schools, mainstream to special education, rural to urban environments, and private to government schools. Eight of the participants were regular classroom teachers in primary or secondary schools. Five of the participants were working in advisory capacities within the Queensland state government education department, and of these all but one started using games in learning when based at a school. The semi-structured interviews were loosely based on an interview guide that explored participants' beliefs about learning, how they have used ICT in learning more broadly, their beliefs about using DGs for student learning and how they have used DGs for student learning.

Interviews were audio recorded, transcribed and analysed using nVivo ComputerAssisted Qualitative Data Analysis Software. Using a Grounded Theory approach, a variety of coding methods and analytical tools were dynamically and flexibly used on the interviews including attribute coding, open-ended, initial coding, subcoding, theming the data, pattern coding, axial coding, theoretical coding, code weaving, theorising (Saldaña 2012), the conditional/consequential matrix and the Paradigm (Corbin and Strauss 2008). We used Theoretical Sampling to guide our data analysis (Corbin and Strauss 2008). That is, questions about an emerging research concept guided the selection of the next set of data to be analysed or re-analysed.

The analysis concluded after reaching Theoretical Saturation (Corbin and Strauss 2008). That is, the 'Being a Believer' process had considerable depth and breadth and the relationships between 'Being a Believer' and other key concepts were clear (Auerbach and Silverstein 2003; Corbin and Strauss 2008). 
Our study offers a shared understanding built between researchers and participants (Kvale and Brinkmann 2009) produced by participants articulating and reflecting on their experiences. We aimed to discover insights and themes about the daily experiences of teachers who have used DGP in the classroom.

To preserve anonymity, this paper does not use participants' real names. Instead pseudonyms generated by a random name generator are used.

Within this paper we have used the convention of italics to denote categories, subcategories and concepts identified during analysis. Quotations from participants are set as 'extract text'. Definitions are set in 'single quote'.

\section{Results and discussion}

Analysis of the interview data indicated that educators who embraced DGP did so because they believed in the power of using DGP in the classroom. Figure 1 shows the process of becoming a believer.

This belief resulted from their success with using DGP in the classroom (see Section 3.1), accessing information and advocacy for using DGP in learning (see Section 3.2) and their personal experiences with DGP (see Section 3.3). These experiences led to them valuing DGP (see Section 3.4). Having positive attitudes towards technology generally (see Section 3.5) and having someone invite them to use DGP in the classroom (see Section 3.6) also facilitated adoption. Many educators feel that being a believer sets them apart from their colleagues (see Section 3.7). We explore these findings in terms of Rogers' (2003) five characteristics of innovation to examine impeding and facilitating factors for the diffusion rate of the use of DGP in classrooms (see Section 3.8).

We define the term believer as 'a person who is persuaded that using DGP in the classroom can be beneficial for learning'.

It's always been something I believe in. (Bernita, secondary school teacher)

[Using DGP] was much better than anything we ... could have come up with ... the kids just [get] excited. (Jennifer, primary school teacher)

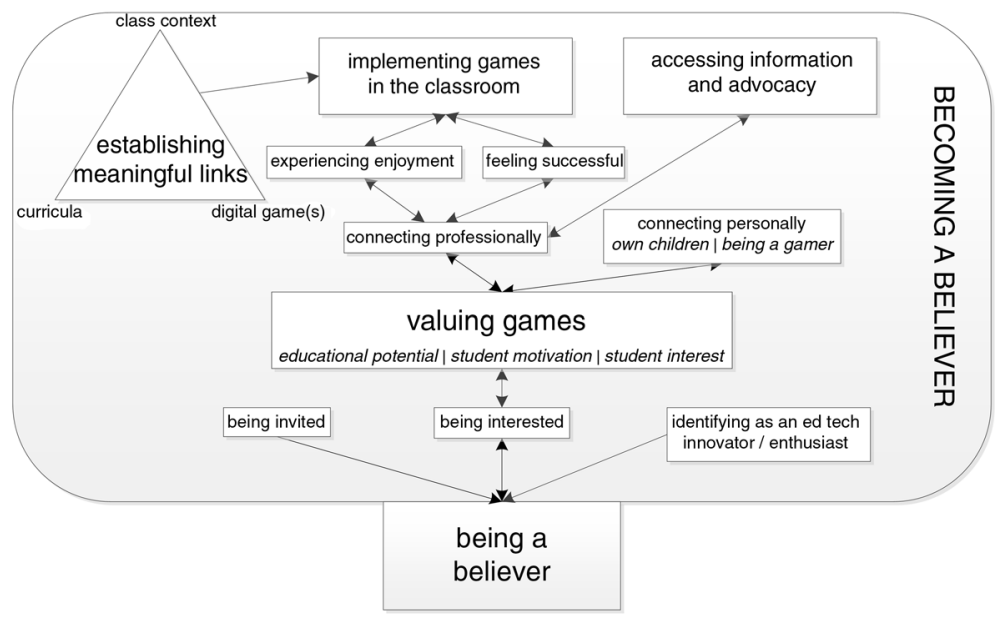

Figure 1. Key themes and relationships to explain the process of becoming a believer in DGP in the classroom. 


\subsection{Success with DGP}

As highlighted in Figure 2, success with DGP began when educators established meaningful links between their class's context, their curricula and the game-play of one or more DGs. The subsequent implementation of DGP in their classroom was both enjoyable and successful and led the educator to feel a professional connection to playing DGs in the classroom.

We define establishing meaningful links between class context and DGs as 'to bring about a significant connection generally during the planning phases between the characteristics of the student cohort (class context) and characteristics of DGP of one or more DGs'. Further, this 'significant connection' required the teachers to be discerning in their choice of DGs. It was not the case that any DG would have done the job, it was that the teachers specifically chose a game because it suited their curriculum and their teaching context. The games chosen ranged from full body movement games to virtual worlds (both those focused on entertainment and education), to simulation games, to car racing games, to learning games. Generally, games with an Australian 'Mature' classification or above were not used. These next quotes show how teachers saw the link between the characteristics of their student cohort and DGP.

I was given a rather interesting class of boys at <location removed $>$ and ahhh, the nature of rural kids is that they can be a bit rough I guess and umm, I ended up having to basically turn away from the original curriculum that we had planned because the boys just weren't going to be interested.... (Miles, secondary school teacher)

We're a National Partnerships' School and I suppose, we are always looking at ways to engage the kids. Cos we have high indigenous population, high level of special needs kids and gaming is just something the kids love. (Jennifer, primary school teacher)

Note: National Partnerships' Schools were identified as having low socio-economic status and lower literacy and numeracy levels (Australian Government 2014).

Further, the teacher was also able to demonstrate establishing meaningful links between curricula and DGs which we define as 'to bring about a significant connection generally during the planning phases between curriculum frameworks developed by

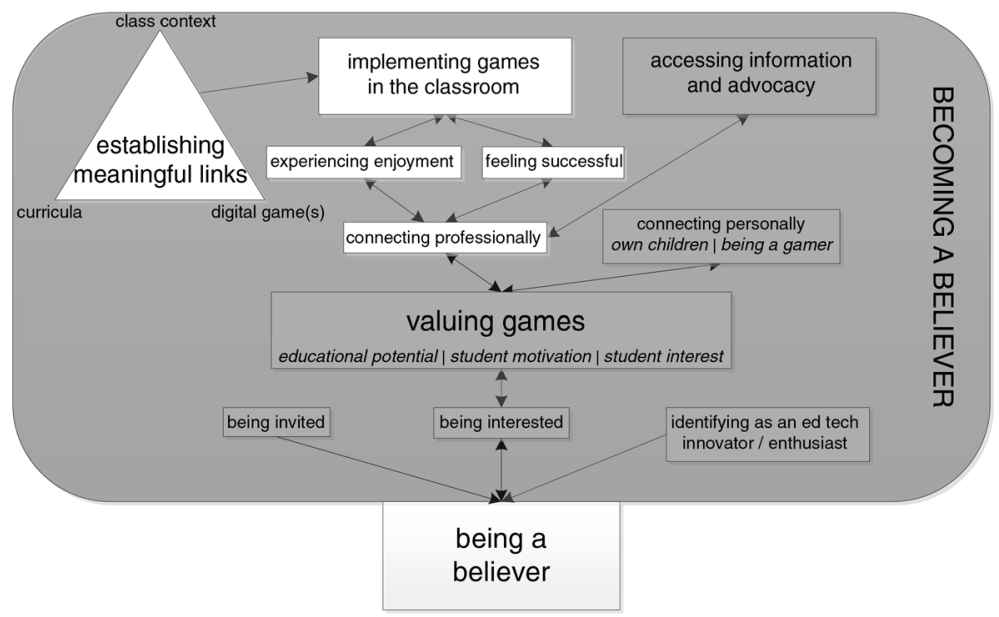

Figure 2. Factors relating to using DGP successfully in the process of becoming a believer. 
education bodies, perceived needs of their student population or the school community's collective beliefs about learning (curricula) and characteristics or elements of DGP of one or more DGs'.

... one of the teachers at school was looking in a gaming magazine and she saw Viva Pinata ... it seemed to match exactly what we were trying to achieve, the kind of knowledge and understanding we want kids to have and the kind of umm, sensitivity around flora and fauna and how they umm, you know inhabit spaces in biomes and how you upset one, you upset the other ... (Esta, primary school Head of Curriculum)

After establishing meaningful links between their class's context, their curricula and one or more digital games, believers implemented DGP in the classroom and felt successful in their use of DGP, they also personally enjoyed the experience of using DGP in the classroom. As indicated by the two-way arrows in Figure 2, the success and enjoyment the teachers felt was not only a result of how they implemented DGP in the classroom but it also made them more willing to use them again in the future.

We define the educator feeling successful with their implementation of DGP in the classroom as 'the teacher perceiving that a desirable or favourable outcome was achieved as a result of the way they used DGP in their classroom'.

I had students who would write just basically ... one or two sentence answers but I found that after they'd been in ... Quest Atlantis it was like they'd been on an excursion ... and then when they came back out ... and put themselves to paper to try and answer the question ... they could tell, like a real story. It was like they could recount an excursion that they'd been on and they could explain their answers in a lot more depth ... they were explaining it to you not just for the sake of putting an answer down but for telling you what they'd seen. (Linn, primary school teacher)

... and they'd start communicating and getting along better by talking about how they'd learnt how to play this or how to do this and it came through in their journals ... [A male student] said he'd never actually talked to this other student in this class until he'd actually, you know, told him how to play this part of a game; and that was another side-benefit of it in terms of, especially bullying. I started to see things like when kids would play things together ... and they had to work together to solve it. All of a sudden, the pay-outs would stop, the sarcasm would stop.... (Miles, secondary school teacher)

These subjective views of success were a result of the teacher's purposeful selection and use of DGs and these feelings of success were not related to the use of a particular genre of DG. Believer teachers also reported that they personally enjoyed teaching using DGP; it was personally fulfilling in ways that their other teaching experiences were not. We define the educator experiencing enjoyment in their implementation of DGP in the classroom as 'the teacher finding pleasure in how they used DGP in the classroom'.

I'm very grateful for it, it's probably the first thing I've had that I can really dig my teeth into. (Miles, secondary school teacher)

I think it's brought a lot more enjoyment for both teacher and student. (Minnie, primary school teacher)

This perceived success of using DGP is the main contributor to the educator connecting professionally to DGP. We define connecting professionally as 'establishing links between DGP, something that may normally be seen only as a fun pastime, with the duties of being a teacher'. 


\subsection{Accessing information and advocacy}

Another contributor to connecting professionally was accessing information and advocacy as highlighted in Figure 3. The teachers in this study accessed information and advocacy as provided by the schooling system (e.g. special games in learning projects, curriculum documents) and professional associations and through reading research. Not only did accessing information and advocacy make the teacher feel more professionally connected to DGP but also educators who had successfully used DGP in the classroom were more likely to access this information and advocacy. We define accessing information and advocacy as 'availing themselves of knowledge about and in-support of using DGP in the classroom'.

I'm heartened by the fact that you can look in the English curriculum and games are mentioned. That's exciting to me. When there's actually ... an educational authority who's saying we want kids to be engaged in popular cultural text and we think that games are a valuable example of that, that's exciting ... It's in black and white, it's in a curriculum document. (Esta, primary school Head of Curriculum)

Once I started to look at the Games in Learning Framework, as outlined by EQ [Education Queensland] it was quite comprehensive and there was parts where I could see English just fit, like especially the game-study component, I mean, you're looking at the issues, the, nature of the game as a text. (Miles, secondary school teacher)

\subsection{Personal experience with games}

Educators who identified as being a believer in DGP had a personal connection to DGP. Several reported being gamers themselves whilst others reported that their personal connection came from watching their own children play DGs as highlighted in Figure 4. We define personal connection as 'the teachers' knowledge and experience of DGs from their private life has led them to believe that DGP would be useful in their classroom'.

A teacher identifying as a gamer explained that this perspective gave him a good understanding of and respect for DGP:

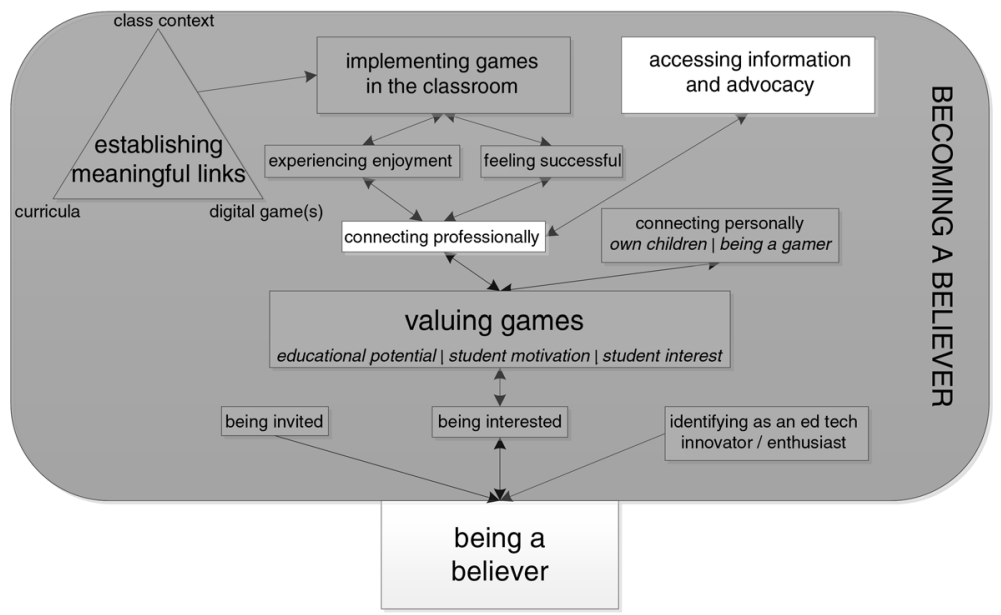

Figure 3. Accessing information and advocacy contributed to connecting professionally. 


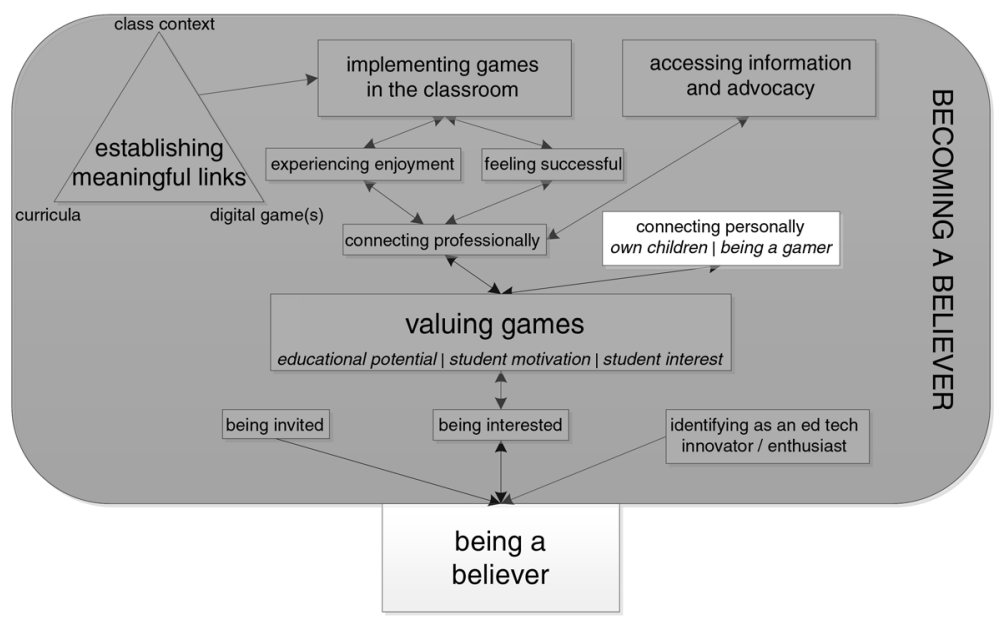

Figure 4. Connecting personally to games leads teachers to value games.

I'm one of those few teachers who has the advantage that I'm an avid gamer as well as an English teacher and I really loved, I saw the potential of what games could do in a classroom, especially a class where ... a lot of kids are disengaged. (Miles, secondary school teacher)

More educators reported their personal interest in DGP stemmed from either playing them with their own children or watching their own children play games.

It doesn't hurt that I have young sons and see the benefits of ... games on a daily basis outside the context of learning. So it was really easy for me to see the power that games would have if embedded in a really rich way in the curriculum. (Esta, primary school Head of Curriculum)

\subsection{Valuing DGP}

The educators' previous personal and professional experiences combine in such a way that they value DGP. The merits that these educators see in DGP is that they have educational potential and are motivating and interesting for students. Further, as the teachers' valuing of DGP grows, it makes them more interested in using DGP in the classroom and vice versa as highlighted in Figure 5. We define valuing DGP as 'believing that there are merits to using DGP in the classroom'.

One of the main merits of using DGP is that believer teachers think DGP has educational potential if selected discerningly and used appropriately. We define educational potential as 'capable of being useful for learning'. Primary school teacher Jennifer explains that there is educational potential in DGP despite the way they are sometimes used in classrooms, ... gaming is just something the kids love, and I am really interested in it. However, I'm really interested in it from the educational point of view, not just from sticking kids on the game to give them some time out.

Teachers also valued DGP because DGP inspires student motivation and student interest. We define student motivation as 'DGs foster a desire to play in students' and student interest as 'DGP captures students' attention and curiosity'. 


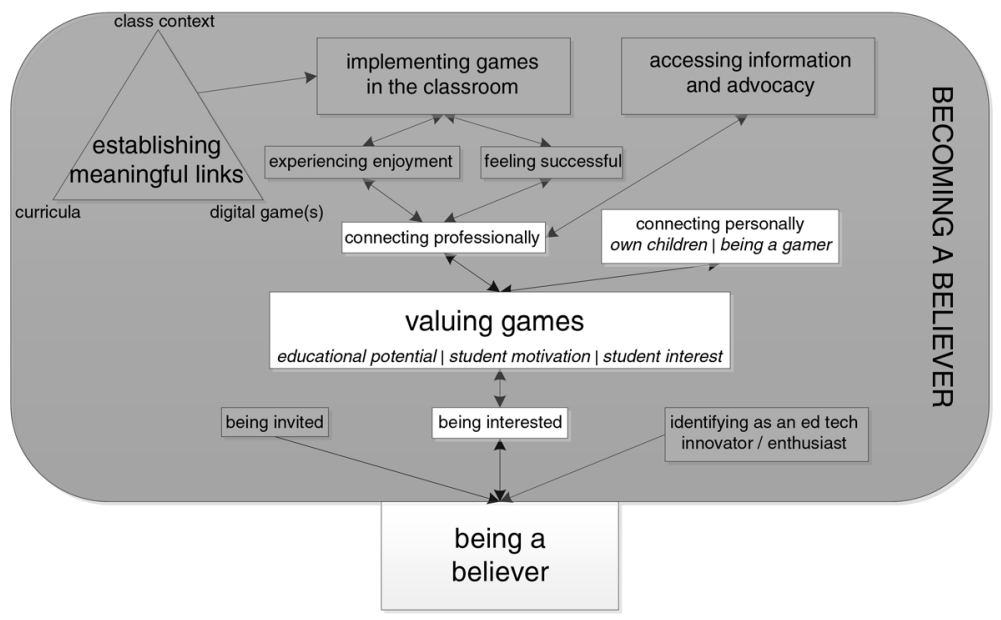

Figure 5. Valuing DGP.

Secondary school teacher Milly observed how motivated by and interested in DGP her students were:

I had kids lining up at the door waiting for me to turn up ... and they love it.

The teacher's value of DGP leads to the teacher also being interested in using DGP in the classroom. We define being interested as 'the teacher is invested in using DGP in the classroom'.

I've always been interested in bringing it into English and I'd seen similar subjects ... taught at other schools. (Miles, secondary school teacher)

\subsection{Positive attitudes towards technology}

All believers interviewed indicated that they saw themselves as an educational technology innovator or enthusiast as highlighted in Figure 6.

We define educational technology innovator or enthusiast as 'the teacher views themselves as someone who wants to use digital technologies to change how things are done in their own teaching as well as being ardently attached to using digital technologies in their own teaching. They also think other teachers should feel the same way'.

Yeah, I like technology, love it, umm, and if you can suit it to the curriculum that you're teaching, umm, more so because the kids really do take it on-board much more. (Jennifer, primary school teacher).

\subsection{Invitation to use games in the classroom}

Another significant factor was that many believers started using DGP in their classroom because someone invited them to do so, whether it be someone from a university or someone from higher up in their schooling system. Therefore, we define being invited as 'a person seen to be in a position of higher knowledge suggests or asks the school/teacher to participate in a DGP project or use DGP in the curriculum' This is highlighted in figure 7. 


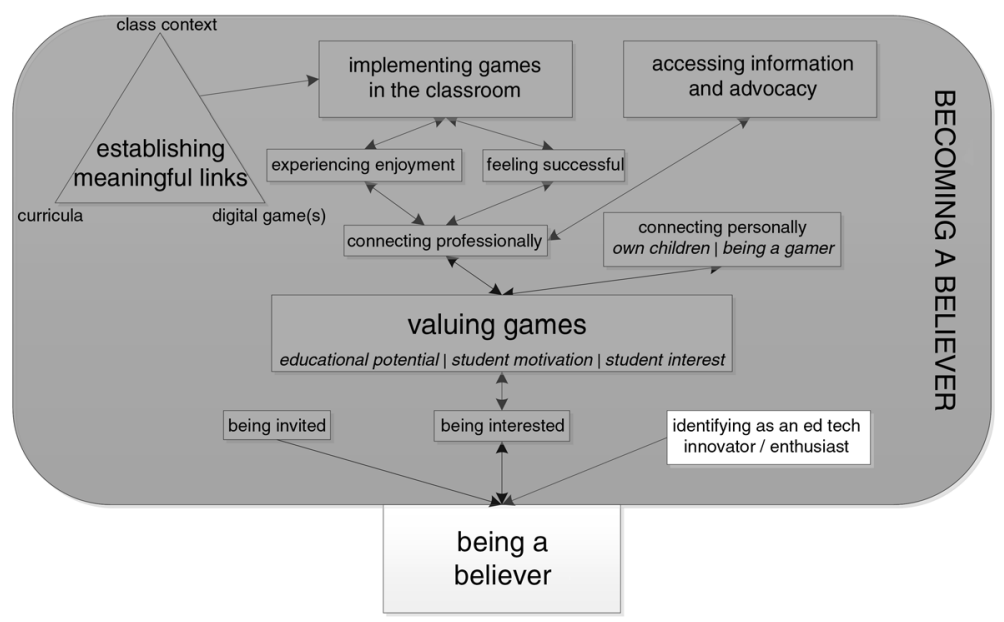

Figure 6. Identifying as an Educational Technology Innovator or Enthusiast is a necessary condition of being a believer in using DGP in the classroom.

I was actually approached by $<<$ name $>>$ who is actually an ICT [Information Communication Technology] consultant of some sort now in EQ but she pointed out the Games in Learning project and asked if I'd like to be involved. (Miles, secondary school teacher)

... we started with a console that was given to us by umm an ICT facilitator of the time for our district ... So when we were offered the opportunity to look at ways to use ... games in the curriculum, we embraced that. Umm, so that was the start of our journey. (Esta, primary school Head of Curriculum)

\subsection{Being different to non-believing colleagues}

Those who were strong believers saw themselves as being different to the majority of their colleagues because they could see the potential for using DGP in the classroom where others could not.

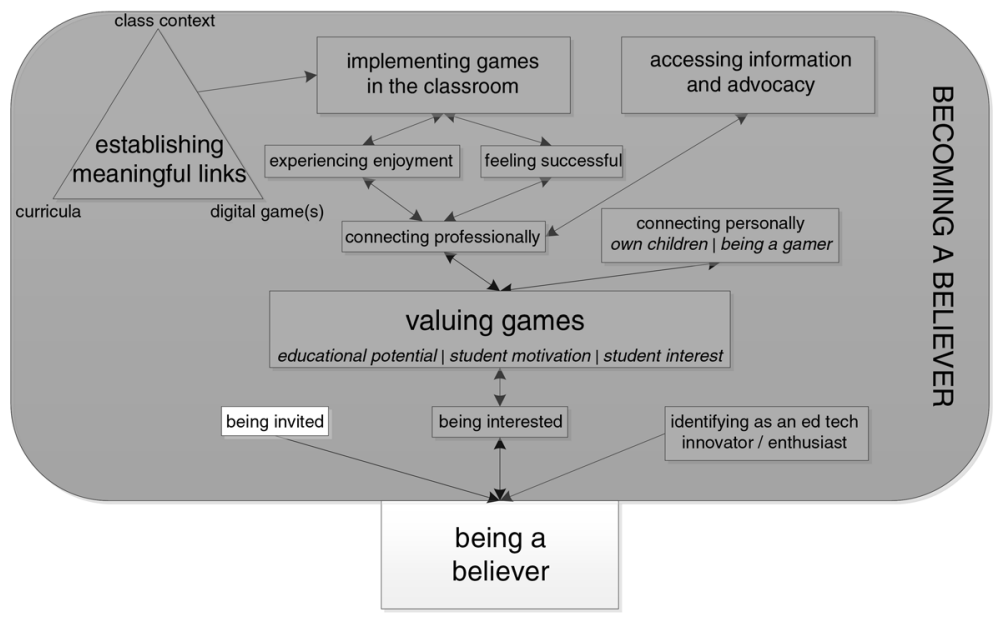

Figure 7. Most teachers who were believers in using DGP in the classroom were initially invited to use DGP by someone seen to be in a position of higher knowledge. 
People who don't play games don't see that [games have educational potential], because they just view it as this old button-mashing ... time waster of the past, let alone something you might actually learn from. (Miles, secondary school teacher)

They [my colleagues] would be very, very nice and say ... 'You were into that sort of thing' ... or, 'I'm a bit too old for that sort of stuff'. All of the comments that they made in a light-hearted way were ways of saying well, 'I'm a traditional teacher and there's no way known that [students playing games] would happen in my classroom.' (Bernita, secondary school teacher)

Some also felt that it had a renewing effect on their teaching practice.

... if I had never actually applied [to a games in learning trial], yeah, I don't know ... I just find that that just opened a whole, new world for me to become. So, I guess, it remotivated and re-invent[-ed] things that I'd been doing the same way ... I think it's brought a lot more enjoyment for both teacher and student. (Minnie, primary school teacher)

\subsection{Implications for the rate of diffusion of the use of DGs in classrooms}

In this section we use Rogers' (2003) Diffusion of Innovations theory to explore the implications of this study for the rate of diffusion of the use of DGP in classrooms. Rogers' (2003) Diffusion of Innovations theory is useful to predict and account for factors impeding or facilitating the diffusion of instructional technologies such as DGs (Kebritchi 2010; Surry and Farquhar 1997). Rogers (2003) describes five 'characteristics of innovations, as perceived by individuals' to help explain adoption rates. These characteristics are (1) relative advantage, (2) compatibility, (3) complexity, (4) trialability and (5) observability.

Relative advantage describes the degree to which the innovation is perceived to be better than what it supersedes. This may be measured in economic terms, social prestige, convenience or satisfaction. The greater the perceived relative advantage, the greater the speed of adoption (Rogers 2003). In this study, believer teachers' feelings of subjective success (feeling successful) and their own feelings of enjoyment whilst using DGP in their classroom (experiencing enjoyment) led them to feel satisfied with their use of DGP. Further, those that were invited by someone in a perceived knowledgeable position (being invited) to use DGP in the classroom could also feel a degree of social prestige as a result of their work. Therefore for believer teachers the perceived relative advantage of using DGP in the curriculum is high, and the degree to which other teachers would perceive this same relative advantage would rely on their ability to comprehend and experience similar feelings of success and enjoyment. We postulate, therefore, that believer teachers who are able to help other teachers experience their own feelings of subjective success and enjoyment, will be more likely to succeed in furthering the use of DGP in their schools.

Compatibility refers to the degree to which the innovation is perceived to be consistent with current values, views and needs (Rogers 2003). Believer teachers find that using DGP is consistent with their current values, views and needs as evidenced by their valuing of DGP in terms of its educational potential, student motivation and student interest. However, many believer teachers also report seeing themselves as being different from the majority of their colleagues in their perceptions of the potential of DGP for the classroom. Therefore, this indicates that the perceived level of compatibility for DGP in the classroom is low for many teachers. 
Complexity refers to the degree to which the innovation is perceived as difficult to understand or use (Rogers 2003). There are two main elements of using DGP in the curriculum that may cause difficulties for educators. Firstly, there can be difficulties using gaming technologies within school infrastructure (e.g. obtaining and using suitable hardware and software). As believer teachers tend to identify as an ED tech innovatorlenthusiast they are more likely than the general teaching populace to be able to navigate technical issues. Secondly, educators need to establish meaningful links between DGP, curricula and class context. Even believer teachers find that these links can be difficult to establish. Therefore, the perceived level of complexity for using DGP in the classroom can be a significant barrier to using DGP in classrooms.

Trialability refers to the degree to which an innovation can be adopted on a limited basis prior to final adoption (Rogers 2003). DGP can be easy to trial and believer teachers describe adopting DGP in limited ways before using them in a more permanent way post-trial. However, some DGs can have licensing or hosting challenges which can limit trialability.

Observability refers to the degree to which results of the innovation are visible to others (Rogers 2003). Unfortunately the believer teachers' successes (feeling successful) with DGP are subjective and not always easily visible to others. For example, believer teachers report that using DGP in the classroom unites the class and provides unexpected motivation. Whilst these are very useful for learning in a classroom setting, they are not easily observable by others.

Rogers' (2003) five characteristics of innovation indicate that the rate of diffusion of using DGP in the classroom will continue to be slow until: (1) there is an improvement in teachers' perceptions of the relative advantage of using DGP in the classroom, (2) the observability of positive results of using DGP in the classroom is increased, (3) the use of DGP in the classroom is made less complex as well as (4) easier to trial and (5) more teachers value the role DGP can have in the classroom.

\section{Conclusions}

Our study has presented the perspective of educators who embraced DGP for which we used the term believers. Similar to our study, Becker (2007) described teachers who had been 'won over' to using DGs in the classroom as 'converts'.

\subsection{Teachers who believe DGP is valuable for their classroom are more likely to use $D G P$ in their classroom}

This study suggests that teachers with a strong belief in the value of DGP for student learning will be more likely to use DGP in their classrooms. Therefore, challenging prevailing teacher attitudes and beliefs towards DGP could lead to an increase in adoption in mainstream classrooms. Similarly, Bourgonjon et al. (2013) found that teachers' perception that DGP was relevant to their practice was crucial for game adoption, therefore they suggest that teacher professional development focus on teacher attitudes before delving into practicalities. Several studies (Can and Cagiltay 2006; Rice 2007; Rosas et al. 2003) found the converse to be true, that teachers' negative perceptions of DGP were a significant barrier to adoption. Therefore, teachers' attitudes towards DGP need to be addressed before addressing the practicalities of using them in a classroom. 


\subsection{Being a parent affects teachers' attitude towards using DGP in the classroom}

Belief in DGP came from both a personal and professional connection to DGP. The personal connection tended to come through teachers' own children playing DGs although some teachers were DG-players themselves. This study found that believer teachers who were also parents took an active interest in their own children's DGP experiences and this contributed to them valuing the way DGP could be used in classrooms. Literature focuses on teachers' personal DGP experiences (Becker and Jacobsen 2005; Bourgonjon et al. 2013; Kenny and McDaniel 2011), rather than their experiences as parents. There is conflicting evidence on whether teachers' DGP experience impacts acceptance of DGP in the classroom. For example, Becker and Jacobsen (2005) found no statistical relationship between teachers' game playing habits and their intention to use games in the classroom whereas Bourgonjon et al. (2013) found that DGP experience was a weak predictor for teachers' intentions to use DGP in the classroom. These studies did not explore how teachers' parental role may impact their perception of the value of DGP in the classroom. Since this is not an area other literature has commonly explored, it warrants further investigation. Our study suggests that teachers who are also parents and take an active interest in their children's DGP will be more likely to have positive attitudes towards using DGP in the classroom.

\subsection{Integrating DGP learning support materials within mainstream and 'official' channels will ensure more teachers consider using DGP}

The professional connection to DGP partly came from the teachers actively seeking information and advocacy on learning involving DGP. Similarly, Becker and Jacobsen (2005) found that teachers perceived that their own efforts to implement learnings from DGP professional development sessions facilitated their use of DGP, whilst Baek (2008) found that teachers identified having inadequate access to support materials as a barrier for using DGP in the classroom. This may explain why the use of DGP in the classroom is not more widespread. Whilst there are professional resources/support materials available to assist teachers to use DGP in the classroom, only the most motivated teachers, such as those participating in this study, are able to find them. Therefore, we recommend that to further increase adoption, DGP learning support materials be integrated throughout the more mainstream and 'official' channels that everyday teachers use for curriculum planning. This includes teaching resources provided by education systems as well as other educational networks.

\subsection{The importance of identifying as an educational technology innovatorlenthusiast}

Our study suggests that self-identifying as an educational technology innovator/ enthusiast was a necessary condition for developing strong beliefs in the value of DGP in the classroom. That is not to say, however, that all teachers identifying as educational technology innovators/enthusiasts will be strong believers in DGP. Bourgonjon et al. (2013) found that the construct 'personal innovativeness' did have a statistically significant but weak impact on teachers' acceptance of DGP, but other factors were more important. They concluded therefore, that attempts to market DGP to teachers as a technological panacea for the classroom would not be effective. This indicates it may be more effective to focus advocacy and DGP learning information on teachers who already use forms of technology other than games, rather than focus on those who do not use technologies. 


\subsection{Teachers experiencing their own form of subjective 'success' are more likely to want to use DGP again}

Believer teachers felt they experienced subjective success when using DGP in the classroom. Similarly, several studies (Becker and Jacobsen 2005; Marino et al. 2013; Rosas et al. 2003) found that teachers' acceptance of DGP in the classroom increased after teachers had used them. None of these studies examined what might happen if a teacher felt that their experience with using DGP was an unsuccessful one. It is evident, however, that teachers in Marino et al. (2013)'s study felt their use of DGP had been successful. For example, teachers in the Marino et al. (2013)'s study believed that the DG prompted more social learning to occur and they felt that it worked well for students who didn't perform well with traditional teaching. This suggests therefore, that in order for teachers to accept DGP, they should be introduced to DGP in a manner that they are most likely to experience success, and in terms that are meaningful to them. Furthermore, as success with DGP in the classroom is subjective, and possibly highly personal and dependant on the class context, teachers should consider how DGP may be able to address classroom needs beyond test scores. This has some similarities to findings in Orlando (2014)'s longitudinal study of classroom teachers and their propensity to change practices using information and communication technologies. She found that teachers are more likely to change their practices towards the use of information and communication technologies if it can be used to 'meaningfully respond' to their personal teaching context and resonate with how they personally see their teaching role.

\section{Limitations}

Since this is a small-scale study based on 13 teachers within Queensland, Australia, more research should be undertaken in other settings and locations. However it does suggest researchers and professional development for teachers must focus on teachers' attitudes to DGP and how they can be used to achieve personal success within their class context.

\section{References}

Auerbach, C. F. \& Silverstein, L. B. (2003) Qualitative Data: An Introduction to Coding and Analysis, NYU Press, New York.

Australian Government. (2014) 'Low socio-economic status school communities', [online] Available at: http://smarterschools.gov.au/low-socio-economic-status-school-communities

Baek, Y. K. (2008) 'What hinders teachers in using computer and video games in the classroom? Exploring factors inhibiting the uptake of computer and video games', CyberPsychology \& Behavior, vol. 11, no. 6, pp. 665-671.

Becker, K. (2007) 'Digital game-based learning once removed: teaching teachers', British Journal of Educational Technology, vol. 38, no. 3, pp. 478-488.

Becker, K. \& Jacobsen, M. (2005) 'Games for learning: are schools ready for what's to come?', DiGRA 2005 Conference: Changing Views - Worlds in Play, Digital Games Research Association DiGRA, Vancouver, Canada.

Bourgonjon, J., et al., (2013) 'Acceptance of game-based learning by secondary school teachers', Computers \& Education, vol. 67, pp. 21-35.

Can, G. \& Cagiltay, K. (2006) 'Turkish prospective teachers' perceptions regarding the use of computer games with educational features', Journal of Educational Technology \& Society, vol. 9 , no. 1 , pp. $308-321$.

Chee, Y. S. (2012) 'Game-based learning initiative', [online] Available at: http://cheeyamsan. info/GLI_StaticArchive/index.html 


\section{Stieler-Hunt and C.M. Jones}

Corbin, J. \& Strauss, A. (2008) Basics of Qualitative Research: Techniques and Procedures for Developing Grounded Theory, 3rd edn, Sage, Thousand Oaks, CA.

Department of Education and Early Childhood Development (Victoria). (2013) 'Games-based learning', [online] Available at: http://www.education.vic.gov.au/about/research/pages/tech gamelearn.aspx

Gee, J. P. (2008) 'Learning and games', in The Ecology of Games: Connecting Youth, Games, and Learning, ed. K. Salen, The MIT Press, Cambridge, MA, pp. 21-40.

Haas, J. (2008) 'The education arcade', [online] Available at: http://www.educationarcade.org

Kebritchi, M. (2010) 'Factors affecting teachers' adoption of educational computer games: a case study', British Journal of Educational Technology, vol. 41, no. 2, pp. 256-270.

Kenny, R. F. \& McDaniel, R. (2011) 'The role teachers' expectations and value assessments of video games play in their adopting and integrating them into their classrooms', British Journal of Educational Technology, vol. 42, no. 2, pp. 197-213.

Kirriemuir, J. \& McFarlane, A. (2004) 'Report 8: literature review in games and learning', Futurelab Series, [online] Available at: http://www.futurelab.org.uk/resources/publicationsreports-articles/literature-reviews/

Kvale, S. \& Brinkmann, S. (2009) Interviews: Learning the Craft of Qualitative Research Interviewing, Sage, London.

Marino, M. T., et al., (2013) 'Students' and teachers' perceptions of using video games to enhance science instruction', Journal of Science Education and Technology, vol. 22, no. 5, pp. 667-680.

McFarlane, A., Sparrowhawk, A. \& Heald, Y. (2002) Report on the Educational Use of Games, Department for Education and Skills, TEEM (Teachers evaluating educational multimedia), Cambridge.

Microsoft Research. (2010) 'Games for learning institute', [online] Available at: http://research. microsoft.com/en-us/collaboration/institutes/gamesinstitute.aspx

Orlando, J. (2014) 'Teachers' changing practices with information and communication technologies: an up-close, longitudinal analysis', Research in Learning Technology, vol. 22, 21354, doi: http://dx.doi.org/10.3402/rlt.v22.21354

Queensland Government. (2008) 'eLearning for smart classrooms', [online] Available at: http:// education.qld.gov.au/smartclassrooms/documents/strategy/pdf/scbyte-elearning.pdf

Rice, J. W. (2007) 'New media resistance: barriers to implementation of computer video games in the classroom', Journal of Educational Multimedia and Hypermedia, vol. 16, no. 3, pp. 249-261.

Rogers, E. M. (2003) Diffusion of Innovations, 5th edn, The Free Press, New York, NY.

Rosas, R., et al., (2003) 'Beyond nintendo: design and assessment of educational video games for first and second grade students', Computers \& Education, vol. 40, no. 1, pp. 71-94.

Saldaña, J. (2012) The Coding Manual for Qualitative Researchers, Sage, London.

Salen, K. \& Zimmerman, E. (2003) Rules of Play: Game Design Fundamentals, MIT Press, Cambridge, MA.

Scottish Government. (2014a) 'Game based learning', [online] Available at: http://www. educationscotland.gov.uk/usingglowandict/gamesbasedlearning/index.asp

Scottish Government. (2014b) 'Game design - game based learning', [online] Available at: http:// www.educationscotland.gov.uk/usingglowandict/gamesbasedlearning/gamedesign/index.asp

Surry, D. W. \& Farquhar, J. D. (1997) 'Diffusion theory and instructional technology', Journal of Instructional Science and Technology, vol. 2, no. 1, pp. 24-36.

The Joan Ganz Cooney Center. (2014a) 'Games and learning publishing council', [online] Available at: http://www.joanganzcooneycenter.org/initiative/games-and-learning-publishingcouncil-analyzing-a-rising-sector/

The Joan Ganz Cooney Center. (2014b) 'Gut sense: using game-based learning to improve STEM achievement', [online] Available at: http://www.joanganzcooneycenter.org/initiative/ gut-sense-using-game-based-learning-to-improve-stem-achievement/

Van Eck, R. (2006) 'Digital game-based learning: it's not just the digital natives who are restless', EDUCAUSE Review, vol. 41, no. 2, p. 16.

Zagami, J. (2012) 'Serious play', ACEC 2012: It's Time to Get Mobile, [online] Available at: http://acec2012.acce.edu.au/sites/acec2012.acce.edu.au/files/proposal/232/ACEC2012-Serious Play.pdf 